\title{
PENGARUH DRYING ELEKTRODA LOW HYDROGEN PADA LONGITUDINAL WELD PENSTOCK MATERIAL BAJA SM 400 B TERHADAP CACAT LAS DENGAN INSPEKSI NON DESTRUCTIVE TEST METODE RADIOGRAFI
}

\author{
Anton Sudiyanto ${ }^{1}$,Riria Zendy Mirahati ${ }^{2}$, Natasya Aulia Rahma ${ }^{3}$ \\ ${ }^{1,2,3}$ Teknik Metalurgi, Fakultas Teknologi Mineral, Universitas Pembangunan Nasional "Veteran" \\ Yogyakarta, \\ Jl. Babarsari No. 2, Tambakbayan, Depok, Sleman, Yogyakarta, 55281 \\ E-mail: anton.sudiyanto@upnyk.ac.id ${ }^{1}$, ririazendymirahati@upnyk.ac.id ${ }^{2}$, natasyarahma118@gmail.com ${ }^{3}$
}

\begin{abstract}
Abstrak
PT. Barata Indonesia (Persero) Divisi Sumber Daya Air Tegal merupakan salah satu workshop hidromekanikal yang berfokus pada pengerjaan bangunan air seperti penstock, katup, trashrack pintu air pada bendungan serta pompa pengendali banjir. Penstock merupakan saluran yang menghubungkan bak penampung air dari bendungan ke turbin di gedung pembangkit listrik. Pada penelitian berjudul "Pengaruh Drying Elektroda Low Hydrogen pada Longitudinal Weld Penstock Material Baja SM 400 B Terhadap Cacat Las Dengan Inspeksi Non Destructive Test Metode Uji Radiografi" ini dilakukan untuk mengetahui perbandingan hasil pengelasan komponen penstock menggunakan perlakuan kondisi elektroda yang didrying dan tanpa drying serta pengaruhnya terhadap cacat pengelasan yang dihasilkan melalui inspeksi non destructive test metode radiografi. Metode pengujian yang pertama dilakukan adalah mencari literaturliteratur penunjang, kemudian pengumpulan data lapangan, melakukan pengujian radiografi, serta pembacaan film dan interpretasi cacat. Parent metal yang digunakan adalah baja SM 400 B yang telah tersertifikasi Mill Test dan memiliki sifat mampu las yang sempurna. Proses pengelasan dilakukan dengan metode SMAW menggunakan elektroda E7016. Berdasarkan penelitian yang telah dilakukan, cacat pengelasan yang teridentifikasi adalah cluster wormhole porosity. Adapun kemungkinan cacat terjadi karena penyimpanan dan perlakuan pemanasan elektroda yang kurang tepat,serta adanya intervensi cuaca akibat pengelasan dilakukan di tempat terbuka.
\end{abstract}

Kata kunci: Cacat, Drying, Elektroda, Pengelasan, Radiografi

\begin{abstract}
PT. Barata Indonesia (Persero) Tegal Water Resources Division is one of the hydromechanical workshops that focus on the construction of water buildings such as Penstock, valves, trashrack water gates on the dam and flood controlling pumps. Penstock is a channel that connects the water reservoir from the dam to the turbine in the power plant building. In the study entitled "The Effect of Low Hydrogen Electrode Drying on Longitudinal Weld Penstock Steel SM 400 B Material Against Welding Defects With Non-Destructive Inspection Test Radiographic Methods" was carried out to determine the comparison of the welding results of the penstock components using the condition of the electrodes being dried and without being drying and its effect on welding defects produced by inspection of the non-destructive test radiography. The first method of testing is to search for supporting literature, collect field data, carry out radiographic testing, film reading and interpretation of defects. The parent metal used is SM 400 B steel which has been Mill Test certified and has perfect weldability. The welding process is carried out using the SMAW method using the E7016 electrode. Based on research that has been done, the welding defect identified is the Wormhole Porosity cluster. As for the possibility of disability occurs because of the insecure storage and treatment of electrodes, and the weather intervention due to welding is carried out in the open.
\end{abstract}

Keywords: defects, drying, electrodes, welding, radiography 


\section{Pendahuluan}

Pengelasan bukan tujuan utama dari konstruksi, tetapi merupakan sarana untuk mencapai pembuatan yang lebih baik serta lebih ekonomis. Karena itu rancangan las dan prosedur-prosedur dalam melakukan pengelasan harus betul-betul diperhatikan kesesuaian antara sifat-sifat las dengan kegunaan konstruksi serta keadaan sekitarnya, sehingga tidak akan menyebabkan terjadinya kesalahan dalam teknik pengelasan yang berujung pada pemakaian biaya yang lebih tinggi. Sampai saat ini telah digunakan lebih dari 40 jenis pengelasan, namun yang sangat lazim dan banyak digunakan pada waktu ini adalah pengelasan cair dengan busur atau lebih dikenal dengan las busur listrik atau Shielded Metal Arc Welding (SMAW). Menurut American Welding Society (AWS) pengelasan adalah proses penyambungan logam atau non-logam yang dilakukan dengan memanaskan material yang akan disambung hingga temperatur las, yang dilakukan dengan atau tanpa menggunakan tekanan dan dengan atau tanpa menggunakan logam pengisi. Definisi tersebut dapat diartikan lebih lanjut bahwa pengelasan adalah suatu aktifitas menyambung dua bagian benda atau lebih dengan atau tanpa bahan tambah (filler metal) yang sama ataupun berbeda titik maupun strukturnya (Alip, 1989).

Pipa pesat (penstock) adalah saluran atau terowongan yang menghubungkan bak penampung air dari bendungan ke turbin di Gedung pembangkit listrik. Penstock merupakan saluran tertutup, biasanya berpenampang lingkaran yang digunakan untuk mengalirkan fluida dengan penampang aliran penuh.

Elektroda las sebaiknya selalu dalam kondisi siap pakai dan kering atau berada di lingkungan yang bebas dari kelembaban untuk menjaga agar elektroda yang akan digunakan selalu berada dalam keadaan kering. Untuk itu perlakuan elektroda setelah dan sebelum pengelasan harus diperhatikan. Berdasarkan penelitian oleh Femiana G. (2007), waktu penyimpanan elektroda di udara terbuka memberikan pengaruh signifikan terhadap porositas. Menurut Irawan (2018), suhu penyimpanan yang tidak sesuai menyebabkan kandungan hidrogen dalam elektroda berubah. Kondisi ini menyebabkan weld ability berubah dan memungkinkan terjadinya porositas dan hydrogen crack (Funderburk, 1997).

Baja SM 400 merupakan baja berstandar JIS G3106, termasuk hot rolled carbon steel plate yang digunakan untuk material pengelasan struktural. SM 400 $\mathrm{A} / \mathrm{B} / \mathrm{C}$ memiliki komposisi yang berbeda, komposisi kimia baja SM 400 dapat dilihat pada Tabel 1.

Tabel 1. Komposisi Kimia Baja SM 400

\begin{tabular}{|c|c|c|c|c|c|}
\hline \multirow{2}{*}{ Symbol } & \multicolumn{5}{|c|}{ Chemical Composition } \\
\cline { 2 - 6 } & C Max & Si Max & Mn & P Max & S Max \\
\hline $\begin{array}{c}\text { SM 400 } \\
\text { A }\end{array}$ & 0.23 & - & $\begin{array}{c}2.5 \times \text { C } \\
\text { min }\end{array}$ & 0.035 & 0.035 \\
\hline $\begin{array}{c}\text { SM 400 } \\
\text { B }\end{array}$ & 0.20 & 0.35 & $0.6-1.40$ & 0.035 & 0.035 \\
\hline $\begin{array}{c}\text { SM 400 } \\
\text { C }\end{array}$ & 0.19 & 0.35 & $1.4 \max$ & 0.035 & 0.035 \\
\hline
\end{tabular}

Sumber : (JIS Handbook, 2010)

Baja SM 400 A/B/C diaplikasikan untuk plat, bar, atau bentuk lain. Memiliki kualitas struktural untuk di rivet, di bolt, atau di las pada jembatan dan bangunan, serta untuk struktural umum. Baja SM 400 memiliki ketebalan yang berbeda 
sesuai dengan kelasnya dapat dilihat pada Tabel 2. Selain itu, Baja SM juga memiliki Energi Penyerapan Charpy yang berbeda sesuai kelasnya yang dapat dilihat pada Tabel 3.

Tabel 2. Designation of Grade dan Applicable Thickness pada Baja SM 400

\begin{tabular}{|c|c|c|}
\hline $\begin{array}{c}\text { Designation of } \\
\text { Grade }\end{array}$ & Steel Product & $\begin{array}{c}\text { Applicable Thickness } \\
(\mathrm{mm})\end{array}$ \\
\hline SM 400 A & $\begin{array}{c}\text { Steel plate, steel strip in coil, } \\
\text { section, and flat }\end{array}$ & $\leq 200$ \\
\hline \multirow{2}{*}{ SM 400 B } & $\begin{array}{c}\text { Steel plate, steel strip in coil, } \\
\text { section, and flat }\end{array}$ & $\leq 200$ \\
\hline \multirow{2}{*}{ SM 400 C } & $\begin{array}{c}\text { Steel plate, steel strip in coil, and } \\
\text { section }\end{array}$ & $\leq 100$ \\
\cline { 2 - 3 } & Flat & $\leq 50$ \\
\hline
\end{tabular}

Sumber : (JIS Handbook, 2010)

Tabel 3. Charp Absorption Energy pada Baja SM 400

\begin{tabular}{|c|c|c|c|}
\hline $\begin{array}{c}\text { Symbol of } \\
\text { Grade }\end{array}$ & $\begin{array}{c}\text { Temperature } \\
\left({ }^{\circ} \mathrm{C}\right)\end{array}$ & $\begin{array}{c}\text { Charp Absorption } \\
\text { Energy }(\mathrm{J}) \text { Minimum }\end{array}$ & Test Piece \\
\cline { 1 - 2 } SM 400 B & \multirow{2}{*}{0} & 27 & $\begin{array}{c}\text { No.4 in rolling } \\
\text { direction }\end{array}$ \\
\cline { 1 - 1 } SM 400 C & 0 & 47 & \\
\hline
\end{tabular}

Sumber : (JIS Handbook, 2010)

Non Destructive Testing merupakan inspeksi terhadap suatu benda untuk mengetahui adanya cacat, retak, atau discontinuity lain tanpa merusak benda yang kita tes atau inspeksi. Biasanya NDT dilakukan selama dan diakhir proses fabrikasi, untuk menentukan suatu komponen dapat diterima setelah melalui tahap-tahap fabrikasi. NDT terdiri dari beberapa metode : Liquid Penetrant Inspection, Eddy Current, Magnectic Test dan Radiography Test. Pengujian Radiography merupakan salah satu metode pengujian tak merusak dengan menggunakan sinar $\mathrm{X}$ atau sinar gamma untuk dapat melihat dan mengidentifikasi jenis cacat las. Prinsipnya, sinar X dipancarkan menembus material yang diperiksa. Saat menembus objek, sebagian sinar akan diserap sehingga intensitasnya berkurang. Intensitas akhir kemudian direkam pada film yang sensitif. Jika ada cacat pada material maka intensitas yang terekam pada film tentu akan bervariasi. Hasil rekaman pada film inilah yang akan memeperlihatkan bagian material yang mengalami cacat.

Kelebihan Pengujian Radiografi adalah persiapan pengujian yang relatif mudah, dapat mendetekasi cacat pada surface dan subsurface, dapat diaplikasikan untuk segala jenis material. Kekurangan Pengujian Radiografi adalah Tidak mudah untuk dioperasikan, butuh keahlian khusus, peralatan yang relatif mahal, waktu operasi yang lama untuk material yang tebal, terdapat resiko efek radiasi pada pengguna.

\section{Metode Percobaan}

Dalam pembuatan spesimen dilakukan beberapa langkah sebagai berikut :

1. Menyiapkan material penstock yaitu baja SM 400 B dengan tebal $16 \mathrm{~mm}$ dan diameter $1200 \mathrm{~mm}$ yang sudah di roll menggunakan mesin rolling

2. Penstock tersebut kemudian dijepit diragum untuk dibuat bevel atau kampuh las dengan menggunakan gerenda tangan. Kampuh las yang dipakai adalah kampuh $\mathrm{V}$.

3. Pengelasan pada spesimen dilakukan dengan proses pengelasan SMAW. Adapun parameter-parameter pengelasan yang digunakan yaitu kuat arus sebesar 200 - 220 Ampere untuk elektroda $\varnothing \quad 2,6 \mathrm{~mm}$, posisi pengelasan 3G, serta jenis arus DCEP. 
4. Pengelasan spesimen yang menggunakan elektroda yang di drying sebelum pengelasan dengan temperatur drying $300^{\circ} \mathrm{C}-350^{\circ} \mathrm{C}$ selama 4 jam dan pengelasan spesimen juga dilakukan dengan menggunakan elektroda tanpa drying yang sudah terkekspos udara bebas.

5. Pengujian Non Destructive Test dilakukan dengan menggunakan metode Radiografi untuk mengetahui indikasi cacat yang dihasilkan.

Adapun flowchart yang digunakan dalam kerja praktik ini adalah sebagai berikut.

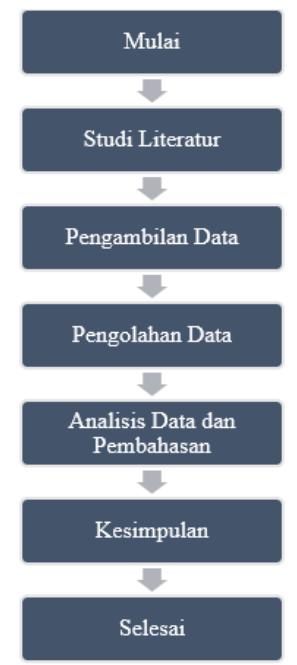

Gambar 1. Flowchart Kerja Praktik

\section{Hasil Penelitian dan Pembahasan 1. Prosedur Pengujian Radiografi}

Adapun prosedur tahapan pengujian radiografi adalah sebagai berikut.

1. Persiapan permukaan: Pada tahapan ini, material yang akan diuji dibersihkan terlebih dahulu permukaan pengelasannya biasanya dengan menggunakan gerinda untuk sedikit membersihkan dan menghaluskan permukaan lasan. Setelah itu, dilakukan pengukuran dimensi terlebih dahulu meliputi, tebal material uji dan tebal pengelasan.

2. Aplikasi pengujian radiografi tes: Setelah permukaan telah dibersihkan dan diukur dimensinya, Langkah selanjutnya adalah sebagai berikut.

a. Pembuatan Sistem Identifikasi: Spesimen yang akan diuji haruslah memiliki identitas, agar data pengujian tidak tertukar. Pembuatan sistem identifikasi ini menggunakan lead marker (plat $\mathrm{Pb}$ )

b. Pembuatan Marker Location: Marker location ini bertujuan utuk memberi tanda lokasi yang ingin diamati (area of interest) agar mudah dalam melakukan penyelidikan terhadap cacat yang terjadi. 3. Penentuan Image Quality Indicator (IQI): Menentukan Image Quality Indicator (IQI) yang akan digunakan berdasarkan pada data hasil pengukuran dimensi ketebalan plat dan disesuai dengan standar pada ASTM Sec.V

4. Source to Object Distance (SOD): Ini merupakan bagian yang paling penting dari prosedur radiografi test dikarenakan pada tahap ini akan ditentukan jarak minimum dari sumber radiasi ke objek/spesimen yang akan diradiografi.

5. Source Film Distance (SFD): Bagian ini mengatur jarak minimum dari sumber radiasi ke film.

6. Exposure time: Ditentukan untuk mengetahui lama waktu yang digunakan untuk mepaparkan sinar X-Ray ke spesimen yang diuji.

7. Loading Film: Dalam proses ini dilakukan dalam ruangan gelap atau dengan bantuan cahaya dari zapp light dengan cahaya lampu warna merah. Cahaya lampu merah ini digunakan karena energinya paling rendah. Hal ini dilakukan agar film tetap terjaga dan tidak menimbulkan artefak pada film. Film yang telah diambil dari tempatnya 
kemudian diapit oleh lead screen dan dimasukkan kedalam kaset film.

\section{Indikasi Cacat Pengelasan Penstock}

Pada pengujian radiografi yang telah dilakukan, terdapat indikasi adanya defect seperti yang ditunjukkan oleh Gambar 2, yaitu porosity. Berdasarkan API 1104, porositas didefinisikan sebagai gas yang terperangkap karena tersolidifikasinya logam las sebelum gas tersebut berhasil keluar dari permukaan molten metal.

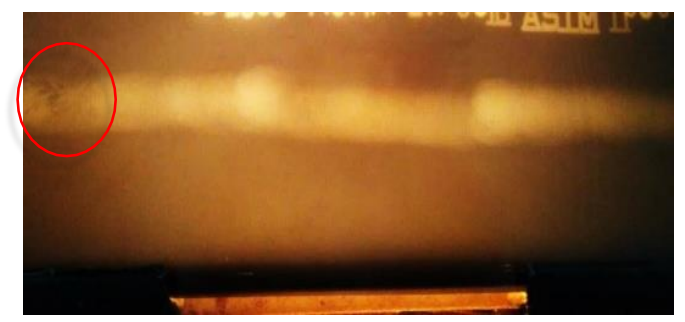

Gambar 2. Indikasi Cacat pada Film Radiografi Longitudinal Weld Joint Nomer 3 Lokasi Film 60-END

Sumber : Divisi Pengendalian Dan Kualitas PT. Barata (Persero) Tegal

Pada Gambar 2 terlihat adanya indikasi cacat berupa sekumpulan porositas yang berbentuk lonjong tak beraturan yang ditunjukkan oleh lingkaran berwarna merah. Indikasi cacat dapat diklasifikasikan sebagai cacat cluster wormhole porosity apabila memenuhi salah satu kriteria diantaranya adalah diameter dari cluster porosity melebihi $13 \mathrm{~mm}$, panjang cluster porosity dalam setiap pengelasan kontinyu sepanjang $300 \mathrm{~mm}$ adalah melebihi $13 \mathrm{~mm}$, dan diameter individual pore dalam suatu cluster porosity melebihi $2 \mathrm{~mm}$. Oleh karena itu, indikasi tersebut dapat dinyatakan sebagai defect cluster wormhole porosity karena melebihi kriteria-kriteria yang telah dijelaskan sebelumnya. Pada Gambar 3 berikut ini merupakan data identifikasi indikasi cacat pada longitudinal weld joint nomor 3 lokasi film 60-END

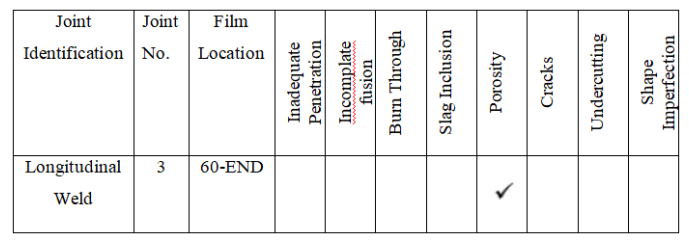

Gambar 3. Identifikasi Indikasi Cacat Pada Longitudinal Weld Joint Nomor 3 Lokasi Film 60-END

Sumber : Divisi Pengendalian Dan Kualitas PT. Barata (Persero) Tegal

3. Perbandingan Hasil Pengelasan Komponen Penstock Dengan Elektroda di Drying dan Tanpa Drying

Pada gambar 4 ini menunjukkan hasil radiografi dari pipa penstock dengan elektroda yang di drying. Sedangkan Gambar 5 menunjukkan data identifikasi indikasi cacat pada longitudinal weld joint nomor 3 lokasi film 60-END.

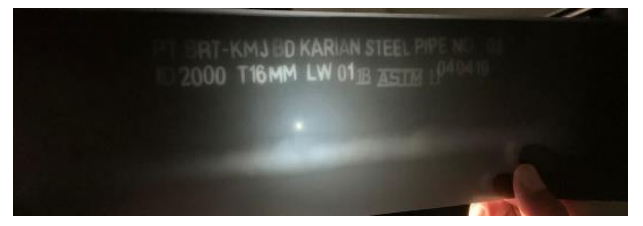

Gambar 4. Hasil Radiografi Test

Longitudinal Weld Joint Nomor 2 Lokasi Film 60-END

Sumber : Divisi Pengendalian Dan Kualitas PT. Barata (Persero) Tegal

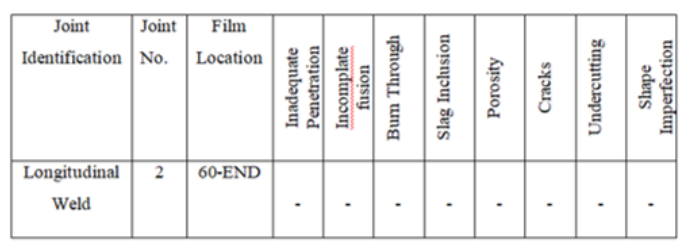

Gambar 4. Identifikasi Indikasi Cacat Pada Longitudinal Weld Joint Nomor 2 Lokasi Film 60-END 
Sumber : Divisi Pengendalian Dan Kualitas PT. Barata (Persero) Tegal

Berdasarkan data hasil uji radiografi pada Gambar 2 dan 4, serta data hasil identifikasi indikasi cacat pada gambar 3 dan 5 ditemukan bahwa terdapat cacat (defect) pada pipa penstock nomor 3 saja. Hal ini, dikarenakan kondisi elektroda pengelasan pada saat digunakan dalam keadaan lembab dan sebelumnya tidak dilakukan proses drying pada suhu tertentu terlebih dahulu, sehingga menimbulkan cacat (defect) berupa porositas cluster pada komponennya. Padahal perlakuan elektroda setelah dan sebelum pengelasan harus diperhatikan. Selain itu, berdasarkan peninjauan langsung ke lapangan, ditemui beberapa elektroda yang digunakan tidak disimpan di tempat khusus atau bahkan dibiarkan tergeletak di luar kemasan. Padahal berdasarkan penelitian oleh Femiana G. (2007), waktu penyimpanan elektroda di udara terbuka memberikan pengaruh signifikan terhadap porositas. Menurut Irawan (2018), suhu penyimpanan yang tidak sesuai menyebabkan kandungan hidrogen dalam elektroda berubah. Kondisi ini menyebabkan weld ability berubah dan memungkinkan terjadinya porositas dan hydrogen crack (Funderburk, 1997). Adapun berdasarkan AWS (2004), bahan pelindung elektroda jenis low hydrogen (E7016) memiliki batas kadar maksimum kelembapan yaitu 0,6\% . Elektroda jenis low hydrogen (E7016) setelah dibuka dari kemasan pabrik haruslah segera disimpan pada suhu $30^{\circ} \mathrm{C}-140^{\circ} \mathrm{C}$ (ASME Sec. II, 2015).
Sebelum dilakukan pengelasan, elektroda yang telah berkontak dengan udara harus dimasukkan ke dalam thermos dengan suhu dan waktu tertentu untuk menghilangkan kelembaban pada elektroda. Selain itu, dijumpai juga elektroda yang hendak digunakan dipanaskan langsung menggunakan api atau elektroda yang sudah dipanaskan di dalam thermos dipanaskan kembali menggunakan api atau didekatkan ke sumber api untuk menghilangkan kelembaban. Menurut Jokosisworo (2006), elektroda haruslah terlindung dari karbon, oksigen, hidrogen, dan nitrogen. Unsur-unsur tersebut dapat dijumpai pada udara, api, dan pengotor permukaan. Adapun seperti yang dijelaskan Werktage (2016) sebelumnya, unsur-unsur tersebut merupakan gas developer penyebab porositas. Sehingga dapat dikatakan cara penghilangan kelembaban elektroda dengan api langsung dapat menyebabkan porositas.

\section{Kesimpulan}

Berdasarkan hasil analisa terkait pengaruh drying elektroda terhadap cacat las PT Barata Indonesia dapat disimpulkan :

a. Metode pengujian diawali dengan melakukan preparasi spesimen, pembuatan sistem identifikasi, pembuatan marker location, penentuan image quality indicator (IQI), menentukan source to object distance (SOD) dan source to film distance (SFD), menentukan exposure time, dan yang terakhir melakukan loading film. Adapun parameter pengujian radiografi yang digunakan diantaranya adalah jenis 
sumber Ir 192, ukuran sumber 3 x 3 $\mathrm{mm}$, teknik radiografi single wall, jenis film Fuji 100, ukuran film 4" $\mathrm{x}$ 15 ", waktu penyinaran 3 menit, SFD 12 inch, IQI ASTM 1B, densitas film 2-4, dan sensitivitas $2 \%$.

b. Cacat pengelasan yang teridentifikasi pada pengelasan longitudinal weld penstock SM 400 B joint no.3 adalah cluster wormhole porosity pada film 60END

4. Hasil pengelasan komponen penstock yang di drying tidak adanya cacat, sedangkan hasil pengelasan komponen penstock yang tidak di drying terdapat cacat berupa porositas. Adapun kemungkinan cacat terjadi karena penyimpanan elektroda yang kurang tepat, perlakuan pemanasan elektroda yang kurang tepat,serta adanya intervensi cuaca akibat pengelasan dilakukan di tempat terbuka.

\section{Ucapan Terima Kasih}

Penelitian ini dapat dilaksanakan dan diselesaikan dengan baik berkat bantuan berbagai pihak. Oleh karena itu penulis mengucapkan terima kasih kepada :

1. PT. Barata Indonesia (Persero) Divisi Sumber Daya Air Tegal

2. Bapak Ir. Anton Sudiyanto M.T., selaku dosen pembimbing dalam penulisan jurnal ini.

3. Bapak Dicnanda Wildan Saputra selaku pembimbing lapangan PT. Barata Indonesia (Persero) Divisi Sumber Daya Air Tegal.

4. Berbagai pihak yang telah ikut berpartisipasi membantu kelancaran kegiatan penelitian, baik secara langsung maupun tidak langsung.
Daftar Pustaka

Alip, M. 1989. Teori dan Praktik Las. Jakarta: Departemen Pendidikan dan Kebudayaan.

American Welding Society. 2004. Certification Manual for Welding Inspectors. AWS: Florida.

ASME Boiler \& Pressure Vessel Code. 2015. Section II - Material.

API 1104. 2018. Welding of Pipelines and Related Facilities. Washington DC: American Petroleum Institute.

Femiana, Wajan B. 2007. Studi eksdperimental Pengaruh kelembaban Elektroda E 7018 terhadap Kualitas Hasil Pengelasan SMAW Plat Baja ASTM283 Grade A. Proseding Seminar Nasional Pasca Sarjana VII Institut Teknologi Sepuluh Nopember Surabaya.

Funderburk, R. S.. 1997. Fundamentals of Preheat Welding Innovation. Vol.XIV No.2.

Werktage. 2005. Fundamentals of Joining Technology Welding, Brazing and Adhesive Bonding. German: ISF Aachen. 